\title{
Employee retention: relationship among housekeeper's job satisfaction, organizational workforce, and racial-ethnicity within the global hospitality industry in Utah, U.S.A. finding stability in a volatile hospitality industry
}

\begin{abstract}
The purpose of this paper is to explore what aspects of organizational workforces and a work environment and motivate the employee and in conjunction of his/her cultural diversity aspect to stay in the organization. This paper is extended to determine the factors reasons for retention of housekeeping employees in hotels in Utah. The researcher has analyzed data collected from 225 respondents and used component factor analysis to extract the factors from 12 organizational workforce variables: job satisfaction, extrinsic rewards, constituent attachments, organizational commitment, organizational prestige, lack of alternative, investments, advancement opportunities, location, organizational justice, flexible work arrangements, non-work influences. The findings indicate that four factors: employee value, rewards, job satisfaction, and organizational commitment are major reasons for the employees' retention in hotels. The findings provide empirical evidence that hotel operator need to aware that the workforce environment is an importance source of employee retention.
\end{abstract}

Keywords: employee retention, job satisfaction, organizational workforce, cultural diversity, factor analysis
Volume 3 Issue I - 2019

\begin{abstract}
Yang Huo
Department of Hospitality Management, Woodbury School of Business, Utah Valley University, USA
\end{abstract}

Correspondence: Yang Huo, Ph.D., CMP,Associate Professor, Hospitality Management, Woodbury School of Business, Utah Valley University, USA, Tel 80I-863-8070, Fax 80I-863-6II2, Email HUOYA@uvu.edu

Received: December 13, 2018 | Published: January II, 2019

\section{Introduction}

Lodging operators have long recognized that quality and productivity rendered by a skilled housekeeper influence customer satisfaction and the inclination to return. Because housekeeping services play an important role in the context of the rendering high quality service to the customer the management of the housekeeping is of critical importance to the success of the hotel operation and business. One of the most laborious roles in the hospitality industry is the housekeeping department. However, the employee turnover rate in the housekeeping department is very high. The Job Openings and Labor Turnover Survey (JOLTS) by The Bureau of Labor Statistics, ${ }^{1}$ shows that the annual average turnover rate from 2013 to 2017 in the hospitality industry is $49.24 \%$ as compared to that of industry average, $23.45 \%$ yielding the turnover rate in the hospitality industry is 2.1times higher that of national industry. This figure is striking since most human resources experts agree a healthy turnover rate should actually be somewhere in the $10 \%-15 \%$. Hotel and motel analysts find and claim that the reason for having a higher employee turnover for housekeepers is that they use their position as a stepping stone as an entry point for a strenuous job, like a front desk clerk (Wells, 2018). Indeed, the excessive employee turnover in the housekeeping department is a costly phenomenon. Recent empirical work confirms that no area of hotel operations suffers more in the turnover issue than housekeeping where operators struggle to fill roles even in major markets and finding housekeeping employees has always been a challenge for hotels. ${ }^{2}$ Therefore, retaining a highly skilled housekeeper remains a primary concern for the hospitality industry. ${ }^{3}$ These claims have increased the scholars' attention to the important role of employee retention in housekeeping operation and hotel property. Most researchers to date have produced results and recommended that the hospitality management need to analyze its organizational workforces in the context of housekeeper's job satisfaction and its relationship with the job performance and cultural diversity since cultural diversity in the hospitality industry abounds in a housekeeping department. ${ }^{4-8}$ Many hotels are making concerted efforts to maintain a skilled and qualified housekeeper through enhanced pay, fringed benefits, and incentive system.

This paper has two primary objectives. The first objective is to identify and determine a framework to generate a theoretically derived set of factors relating to employee retention and employees' reasons to stay/leave that would serve as a foundation to determine the housekeeper's perceptions of labor mobility and job satisfaction. The second, and primary, objective is to explore what aspects of organizational workforces and a work environment and motivate the employee and in conjunction of his/her cultural diversity aspect to stay in the organization. The exploratory research study is centered on the question: What are some factors to prevent turnover and promote the housekeeper retention? The objective is to examine what motivational organizational culture is given by the hotel property to keep their skilled housekeepers and to let them provide quality service to the customer as observed by the housekeeping department employees.

\section{Literature review}

March \& Simon, ${ }^{8}$ initiated the model of employee turnover through the theory of organizational equilibrium where the authors proposed that desirability of movement and ease of movement are the two main drivers of employee turnover. The model suggests that employees 
will be more likely to stay when they are satisfied with their jobs and believe that there are few alternatives available. Porter \& Steers, ${ }^{9}$ introduced one of the first major updates to the March and Simon model, and determined that two major dimensions such as extrinsic rewards and advancement opportunities are critical factors related to stay and retention. Since then many other explanatory constructs in the context of employees' decision to remain have evolved in the retention literature. Wilton (2006) claimed that the need for service quality increases, the need to recruit and retain suitable employees also increases. Sim et al. ${ }^{10}$ designed a model of customer satisfaction and retention for hotels for relationship among added value, gender, customer satisfaction and retention. Through the evolved retention factors in the leisure and hospitality industry, ${ }^{3}$ developed a content model of 12 retention factors and found that job satisfaction, extrinsic rewards, constituent attachments, organizational commitment, and organizational prestige were the most frequently mentioned reasons to stay. They conducted a study that focused on the reasons for employees staying in an organization and lamented on the vast amount of literature on labor turnover and discovered that to retain quality employees, talent management was a very important factor in the competitiveness and success of an organization. The global hospitality industry also has recognized that a employee turnover is an emerging problem and provided an attention of researchers worldwide. ${ }^{11}$ conducted a study in the Jordanian hotel sector and data were collected from 250 employees and found that in which more than $50 \%$ of the employees surveyed intended to leave the sector. ${ }^{12}$ explored determinants of management-level-employee turnover and identified existing practices in human resources retention strategies in international tourist hotels in Taiwan and found that more than $80 \%$ of managers had resigned from a job to pursue career advancement. These studies have shown how retention factors can leads to employee satisfaction or dissatisfaction, yields employee reasons to stay or to leave. Finally, it creates multiplier effect on service quality, job performance, and eventually on guest satisfaction and loyalty to a hotel (Figure 1). The incidence of high turnover rates of housekeeping department are very critical in the hotel industry rendering high quality service to the customers and retaining them is crucial toward maximization of hotel efficiency. However, much of the research has been focused on identifying the causes of turnover and formulating strategies for general areas of hotel operation such as front office, food \& beverage department. Little attention however, has been given to identify the actual effect of turnover on the work forces of the organization in the context of retention of housekeeping department.

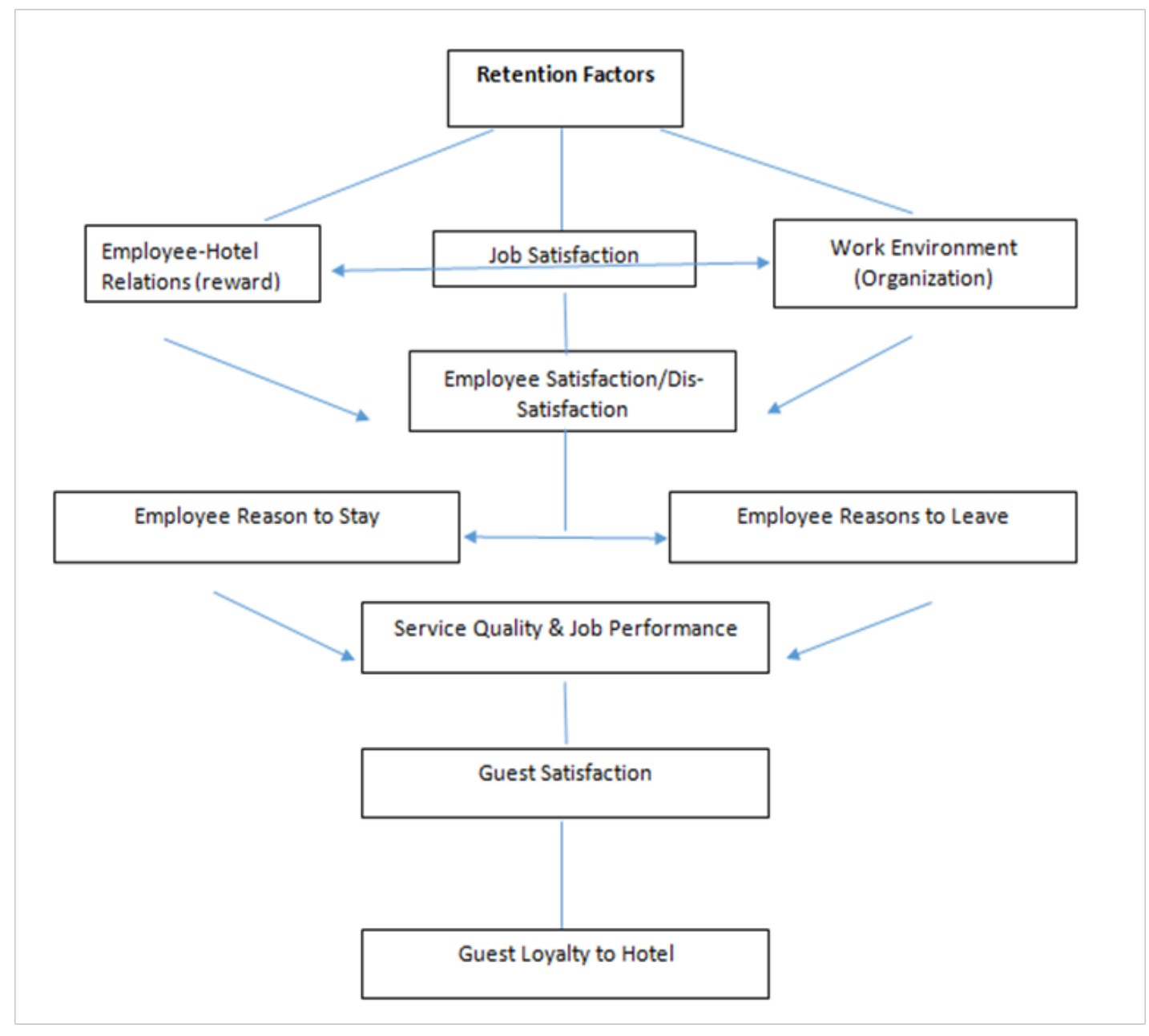

Figure I Theoretical Framework. The relationship between retention factors and employee satisfaction on reason to stay determination, service quality, and guest loyalty. 


\section{Methodology}

\section{Sample and data collection}

The sample consisted of housekeeping department employees of hotels in Utah. The unit of analysis was what aspects of organizational workforces and a work environment factors and motivate the employee and in conjunction of his/her cultural diversity aspect to stay in the organization. A content model of 12 attributes of was developed and augmented in the context of previous studies, ${ }^{3,13,14}$ (Figure 1). A self- administrated mail survey instrument was developed in English (Table 1) and translated in Spanish as well since the major housekeepers are Hispanic background (Table 2) and the survey questionnaire was distributed to housekeeping department employees. Respondents were asked on the survey to indicate the overall rating on 12 attributes. Ratings are made on a 5-point Likert Scale: 5=Extremely Important, $4=$ Very Important, $3=$ Important, $2=$ Slightly Important, and $1=$ Not important. Usable responses were received from 10 hotels and resulted for 225 (yielding $75 \%$ response rate).

Table I Retention factors and description

\begin{tabular}{|c|c|}
\hline Retention factors & Description \\
\hline Job satisfaction & The degree to which individuals like their jobs \\
\hline Extrinsic rewards & The amount of pay, benefits, or equivalents distributed in return for service \\
\hline $\begin{array}{l}\text { Constituent } \\
\text { attachments }\end{array}$ & $\begin{array}{l}\text { The degree of attachment to individuals associated with the organization such as supervisor, co- } \\
\text { workers, or customers }\end{array}$ \\
\hline $\begin{array}{l}\text { Organizational } \\
\text { commitment }\end{array}$ & The degree to which individual's identify with and are involved in the organization \\
\hline $\begin{array}{l}\text { Organizational } \\
\text { prestige }\end{array}$ & The degree to which the organization is perceived to be reputable and well-regarded \\
\hline Lack of alternatives & Beliefs about the unavailability of jobs outside of the organization \\
\hline Investments & Perceptions about the length of service to the organization \\
\hline $\begin{array}{l}\text { Advancement } \\
\text { opportunities }\end{array}$ & The amount of potential for movement to higher levels within the organization \\
\hline Location & The proximity of the workplace relative to one's home \\
\hline Organizational justice & $\begin{array}{l}\text { Perceptions about the fairness of reward allocations, policies and procedures, and interpersonal } \\
\text { treatment }\end{array}$ \\
\hline $\begin{array}{l}\text { Flexible work } \\
\text { arrangements }\end{array}$ & The nature of the work schedule or hours \\
\hline Non-work influences & The existence of responsibilities and commitments outside of the organization \\
\hline
\end{tabular}

Notes: Several factors and descriptions augmented and adopted from; Chan \& Kuok, 20I I; Hausknecht, Rodda, Howard 2008, 2009; Lee \& Lee, 2012

Table 2 Retention factor survey form: Spanish

What are the two or three main reasons why you remain employed at Hote and not with competitors?

Satisfaction at work: How much you like your job

Extrinsic rewards:Amount in salary, benefits or equivalents distributed in exchange for work

Constituent attachments: The degree of union with the people that I have managed to know here prevents me from leaving the organization such as the supervior, colleagues or clients.

Organizational commitment:The degree to which each individual identifies and becomes involved with the organization

Organizational prestige:The degree to which the organization is perceived in good standing and well recognized

Lack of alternatives: Beliefs about the non-existence of job opportunities outside the organization

Investment: Perceptions about the level of service to the company

Opportunities for promotion:The potential for promotion to higher levels in the company organization

Location:The proximity to the workplace at home

Organizational Justice: Perception of equality in appointments and rewards, policies and procedures of the company and personal treatment

Flexible work organization:The nature of the work shift and the hours

Non-existence of influences at work:The existence of responsibilities and commitments outside the workplace 


\section{Data analysis \& findings}

The survey questionnaire regarding the demographics of housekeeping department in the hotel was constructed to identify the cultural environment and whether it influences on the organizational work force. In this questionnaire all the participants were asked to provide ethnicity, gender, age, and years of work experience in the housekeeping department. The simple descriptive statistics showing the profile/demographic of the sample housekeeping department employees is shown in (Table 3). The demographic shows that majority of housekeeper is Hispanic $(\mathrm{n}=155,68.9 \%)$ followed by Asian $(\mathrm{n}=55,24.4 \%)$ which indicates that more than 93 percent of labor of housekeeping department employees are minority and a cultural diversity is a key component in the work environment in the hotel industry. The work force in the housekeeping department shows that female is a dominant gender $(\mathrm{n}=160,71.1 \%)$ compared to male $(n=65,28.9 \%)$. The age of housekeeper describes that less than 30 years old $(n=91,40.5 \%)$ while more than 30 years old takes more than $59.5 \%$ of work force in the housekeeping department. This age group plays important work force in the housekeeping department. The years of housekeeping job experience also indicate that more than 61 percent housekeeper works less than ten years in the housekeeping department which shows a higher portion of employee turnover ratio (Table 3).

Table 3 Demographic of respondents, housekeepers

\begin{tabular}{|c|c|c|c|c|}
\hline \multirow{2}{*}{$\begin{array}{l}\text { Demographic } \\
\text { Ethnicity }\end{array}$} & \multicolumn{2}{|c|}{ Respondents } & \multicolumn{2}{|c|}{ Percentage } \\
\hline & & & & \\
\hline & Hispanic & 155 & & 68.9 \\
\hline & Asian & 55 & & 24.4 \\
\hline & Caucasian & 13 & & 5.8 \\
\hline & Other & 2 & & 0.9 \\
\hline \multicolumn{5}{|l|}{ Gender } \\
\hline & Male & 65 & & 28.9 \\
\hline & Female & 160 & & 71.1 \\
\hline \multicolumn{5}{|l|}{ Age } \\
\hline & $<20$ & & 15 & 6.7 \\
\hline & $21-30$ & & 76 & 33.8 \\
\hline & $31-40$ & & 83 & 36.9 \\
\hline & $4 I-50$ & & 40 & 17.8 \\
\hline & Over 50 & & II & 4.9 \\
\hline \multicolumn{5}{|c|}{ Years of Housekeeper } \\
\hline & $1-5$ & & 81 & 36 \\
\hline & $6-10$ & & 56 & 24.9 \\
\hline & $11-15$ & & 35 & 15.5 \\
\hline & $16-20$ & & 31 & 13.8 \\
\hline & Over 2I & & 22 & 9.8 \\
\hline
\end{tabular}

Note. Total Respondents $(n)=225 / 100 \%$

A factor analysis using a correlation matrix of the variables $(\mathrm{R}$ factor analysis) was performed since the unit of was to summarize the variables and to condense/reduce contributing factors from job satisfaction factors, rewards, organizational workforces, position level, and racial-ethnicity and to condense/reduce contributing factors. A calculation of the input data with a correlation matrix shows the inter correlations among all variables and defines a small number of factors that adequately represent the original set of variables. ${ }^{15}$ Table 4 shows the correlation matrix for the 12 attributes of workforce environment and inspection of the correlation matrix shows that 25 of the 66 correlations (38\%) are significant at the .01 level, which provides an adequate basis for proceeding to an empirical examination of adequacy for factor analysis on both an overall basis and for each variables and reliability of variables (Table 4).

The measure of sampling adequacy (MSA) is needed for factorability of the overall set of variables and individual variables and the Bartlett test is to be assessed for the overall significance of the correlation matrix..$^{15}$ The Measure of Sampling Adequacy (MSA) showing $M S A=.792$ indicates the degree of inter correlation is meritorious and quantify the degree of inter correlations among the variables and Bartlett's test of sphericity:.000(sig.<.05): indicates that sufficient correlations exist among the variables to proceed for the factor extraction method. The principle component analysis was used as the objective is to summarize most of the original information (variances) in a minimum number of factors for prediction purposes, data reduction (Table 5).

Varimax rotation which simplifies the columns (factors) of the factor matrix making as many values in each column as close to zero as possible (making number of high loadings as few as possible) was used. Given the sample size of 225 , factor loadings of .40 and higher is considered significant for interpretative purpose and factors with Eigenvalues (Latent Roots) greater than 1.0 are significant factors and retainable factors. The scree test (Figure 2) indicates that five factors may be appropriate when considering the changing eigenvalues. In viewing the eigenvalue for the fifth factor, its low value (.75) relative to the latent root criterion value of 1.0 preclude its inclusion. The four factors retained represent 77.8 percent of the variance of 12 variables which deem sufficient in terms of total variance explained (Table 8) (Table 6) and (Figure 2). As shown in Table 7 only flexible work arrangement has a communality that is low (.403) indicates it is poorly accounted for by the factor solution and it is deleted from the loading.

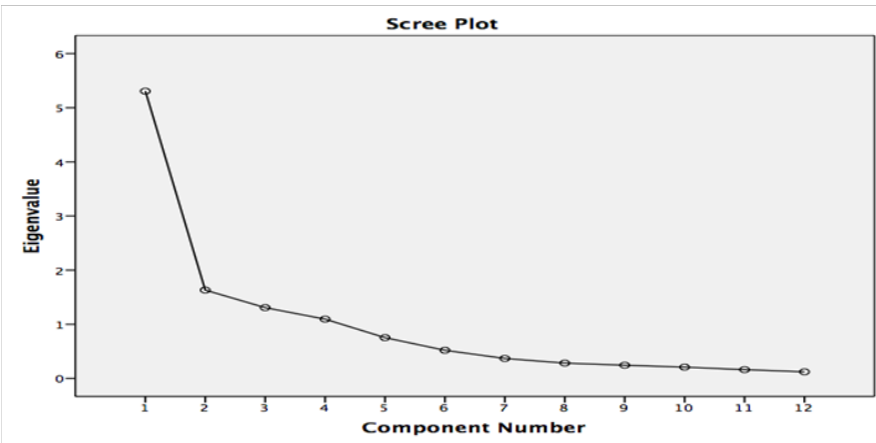

Figure 2 Scree test plot for component analysis.

The rotated component matrix shown Table 10 organizational justice (.872), advancement opportunity (.856), and investment (.851) and all load highly on factor 1 ; factor 2 is characterized by variables Extrinsic Reward (.908), Constituent (.858), and factor 3 has one variable Job Satisfaction (.937) and factor 4 has also one variable organizational commitment (.966) respectively (Table 9). Each factor is named based on the variables with significant loadings and based on the characteristics of variables in each factor as follows: 
Factor 1 Employee Value: organizational justice, perceptions about the fairness of reward allocations, policies and procedures, and interpersonal treatment; advancement opportunities, the amount of potential for movement to higher levels within the organization; investment, perceptions about the length of service to the organization.

Factor 2 Rewards: extrinsic rewards, the amount of pay, benefits, or equivalents distributed in return for service; constituent attachments, the degree of attachment to individuals associated with the organization such as supervisor, co-workers, or customer.
Factor 3 Job satisfaction: the degree to which individuals like their jobs.

Factor 4 Organizational commitments: the degree to which individual's identified with and are involved in the organization.

Based on the analysis of housekeeper's responses from the hotels the relative importance of reasons to stay is found in conjunction with the job satisfaction, job performance, and racial-ethnicity exclusively. The findings also highlight the importance of the organizational workforce and reasons to stay.

Table 4 Correlation matrix between and among variables in the retention

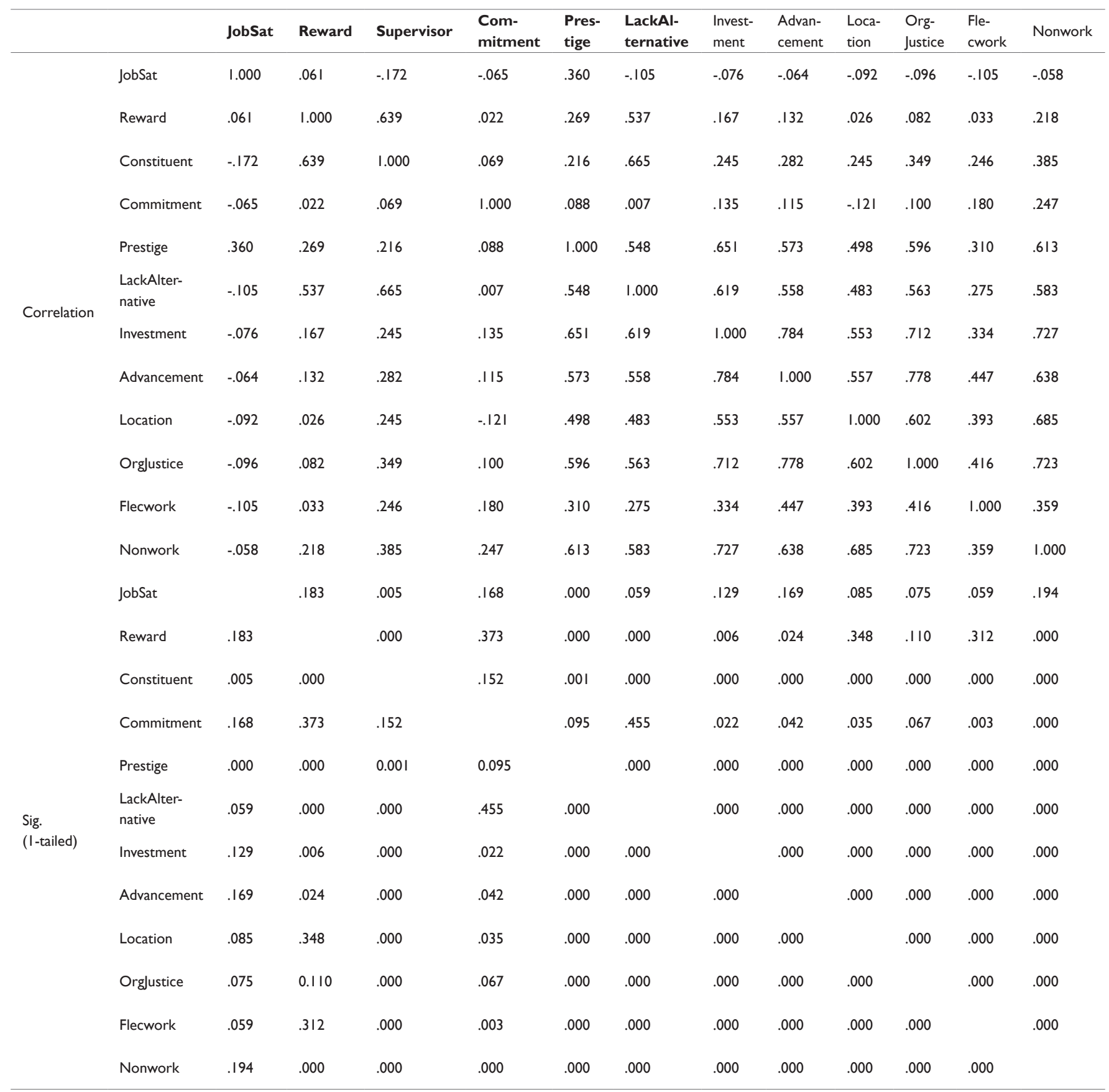


Table 5 KMO and Bartlett's test results

\begin{tabular}{lll}
\hline Kaiser-Meyer-Olkin Measure of Sampling Adequacy & 0.792 \\
& Approx. Chi-Square & 1663.029 \\
Bartlett's Test of Sphericity & df & 66 \\
& Sig. & 0 \\
\hline
\end{tabular}

Table 6 Results for the extraction of principal component analysis

\begin{tabular}{llll}
\hline \multirow{2}{*}{ Component } & \multicolumn{3}{l}{ Initial Eigenvalues } \\
\cline { 2 - 4 } & Total & \% of Variance & Cumulative \% \\
\hline 1 & 5.306 & 44.219 & 44.219 \\
2 & 1.632 & 13.597 & 57.817 \\
3 & 1.307 & 10.895 & 68.712 \\
4 & 1.095 & 9.123 & 77.835 \\
5 & .753 & 6.277 & 84.112 \\
6 & .519 & 4.328 & 88.44 \\
7 & .369 & 3.072 & 91.512 \\
8 & .283 & 2.356 & 93.868 \\
9 & .244 & 2.032 & 95.899 \\
10 & .208 & 1.734 & 97.634 \\
11 & .162 & 1.349 & 98.983 \\
12 & .122 & 1.017 & 100.000 \\
\hline
\end{tabular}

Table 7 Results of communalities

\begin{tabular}{lcc}
\hline & Initial & Extraction \\
\hline Job Sat & 1.000 & .889 \\
Reward & 1.000 & .852 \\
Constituent & 1.000 & .828 \\
Commitment & 1.000 & .939 \\
Prestige & 1.000 & .843 \\
Lack Alternative & 1.000 & .816 \\
Investment & 1.000 & .759 \\
Advancement & 1.000 & .753 \\
Location & 1.000 & .722 \\
Org Justice & 1.000 & .778 \\
Flexible work & 1.000 & .403 \\
Nonwork & 1.000 & .757 \\
\hline
\end{tabular}

Extraction Method: Principal Component Analysis.

Table 8 Total variance explained

\begin{tabular}{|c|c|c|c|c|c|c|c|c|c|}
\hline \multirow[t]{2}{*}{ Component } & \multicolumn{3}{|c|}{ Initial Eigenvalues } & \multicolumn{3}{|c|}{$\begin{array}{l}\text { Extraction sums of squared } \\
\text { loadings }\end{array}$} & \multicolumn{3}{|c|}{ Rotation sums of squared loadings } \\
\hline & Total & $\begin{array}{l}\% \text { of } \\
\text { Variance }\end{array}$ & $\begin{array}{l}\text { Cumulative } \\
\%\end{array}$ & Total & $\begin{array}{l}\% \text { of } \\
\text { Variance }\end{array}$ & $\begin{array}{l}\text { Cumulative } \\
\%\end{array}$ & Total & $\%$ of Variance & Cumulative \% \\
\hline I & 5.306 & 44.219 & 44.219 & 5.306 & 44.219 & 44.219 & 4.711 & 39.259 & 39.259 \\
\hline 2 & 1.632 & 13.597 & 57.817 & 1.632 & 13.597 & 57.817 & 2.196 & 18.303 & 57.562 \\
\hline 3 & 1.307 & 10.895 & 68.712 & 1.307 & 10.895 & 68.712 & 1.301 & 10.843 & 68.405 \\
\hline 4 & 1.095 & 9.123 & 77.835 & 1.095 & 9.123 & 77.835 & 1.132 & 9.43 & 77.835 \\
\hline 5 & .753 & 6.277 & 84.112 & & & & & & \\
\hline 6 & .519 & 4.328 & 88.44 & & & & & & \\
\hline 7 & .369 & 3.072 & 91.512 & & & & & & \\
\hline 8 & .283 & 2.356 & 93.868 & & & & & & \\
\hline 9 & .244 & 2.032 & 95.899 & & & & & & \\
\hline 10 & .208 & 1.734 & 97.634 & & & & & & \\
\hline II & .162 & 1.349 & 98.983 & & & & & & \\
\hline 12 & .122 & 1.017 & 100.000 & & & & & & \\
\hline
\end{tabular}

Extraction method: principal component analysis. 
Table 9 Component matrix ${ }^{a}$

\begin{tabular}{lllll}
\hline \multicolumn{5}{l}{ Component } \\
& 1 & 2 & 3 & 4 \\
\hline JobSat & -.062 & -.083 & .911 & .221 \\
Reward & .352 & .828 & .185 & .094 \\
Constituent & .537 & .713 & -.177 & -.008 \\
Commitment & .147 & -.061 & -.272 & .916 \\
Prestige & .749 & -.112 & .504 & .123 \\
LackAlternative & .796 & .41 & .016 & -.119 \\
Investment & .849 & -.194 & .024 & .008 \\
Advancement & .837 & -.226 & -.041 & -.01 \\
Location & .726 & -.253 & -.033 & -.362 \\
Orgjustice & .85 & -.22 & -.07 & -.054 \\
Flecwork & .518 & -.186 & -.273 & .161 \\
Nonwork & .858 & -.109 & -.03 & .091 \\
\hline
\end{tabular}

Extraction method: principal component analysis, a. 4 components extracted.

Table I 0 Rotated component matrix

\begin{tabular}{lllll}
\hline & \multicolumn{4}{l}{ Component } \\
\cline { 2 - 5 } & $\mathbf{I}$ & $\mathbf{2}$ & $\mathbf{3}$ & \multicolumn{1}{l}{$\mathbf{4}$} \\
\hline Job Sat & -.082 & -.059 & .937 & -.032 \\
Reward & -.014 & .908 & .162 & .026 \\
Constituent & .224 & .858 & -.197 & .044 \\
Commitment & .081 & .017 & -.012 & .966 \\
Prestige & .697 & .214 & .556 & .041 \\
Lack of Alternative & .582 & .686 & -.01 & -.082 \\
Investment & .851 & .156 & .073 & .07 \\
Advancement & .856 & .119 & .007 & .07 \\
Location & .799 & .041 & -.079 & -.276 \\
Org Justice & .872 & .127 & -.032 & .037 \\
Flex work & .542 & .026 & -.187 & .272 \\
Nonwork & .821 & .238 & .038 & .160 \\
\hline
\end{tabular}

Extraction method: principal component analysis, rotation method: varimax with Kaiser normalization, a. rotation converged in 4 iterations.

\section{Discussion, conclusion, and recommendation for the future research}

This study is one of the first housekeeping department samples and cross cultural diversified empirical tests to determine an employee retention factor in the hotel industry. While it is not possible in this research to identify all of the factors that account for the retention variables, the fact that the work environments provided by the hotel property strongly impact on housekeeping department employees' reasons to stay/remain in the organization longer and provide a highquality job performance to the property and the customer as well. Furthermore, this research and its findings provide empirical evidence that organizational workforce improves job satisfaction and play an important role in quality and productivity to the racial-ethnicity work environment. In addition, the findings suggest that the hospitality management should consider how effective retention management strategies and workforces influence the racial and cultural diversity demographics as they play very important roles in the service-oriented industry and their attitudes and behavior may not be in parallel with the traditional organizational culture. This confirms the results of other studies that have reported significant links between workforce environment such job satisfaction and retention. ${ }^{13,3,14}$ However, in contradiction to prior research, this study finds that the participants from housekeeping departments claim that the reward is the most important factor to stay in the same organization for a long period and to provide a high-quality job performance to the operation as well as to the hotel guest. These findings also have implications for how housekeeping department management team in a hotel property can maximize employee value which is measured by an extrinsic reward such as pay, benefits, or equivalents distributed in return for their service. This reward can simultaneously trigger the employee's appreciation for the management and increase the royalty to the hotel property and overall the hotel operator can lower the costs of hiring new housekeeping department employees. It is also important to note that the hotel operator need to aware that the chance of employees' turnover to other organization is very high as long as they have not recognized their rewards or value for their contribution to the hotel property are lower than expected. Future empirical research could shed light on determining the correlation between demographics such as ethnicity, age, gender, years of experience, and retention factors and defining and constructing the multiple regression analysis by identifying how weight of each factors contribute to the reasons to stay in the same organization for a long period (Table 11). ${ }^{16}$

Table I I Component transformation matrix

\begin{tabular}{lllll}
\hline Component & I & $\mathbf{2}$ & $\mathbf{3}$ & $\mathbf{4}$ \\
\hline I & 0.916 & 0.392 & $0.04 I$ & 0.07 \\
2 & -0.387 & 0.919 & -0.066 & -0.047 \\
3 & -0.04 & 0.039 & 0.962 & -0.267 \\
4 & -0.097 & 0.028 & $0.26 I$ & 0.96
\end{tabular}

Extraction method: principal component analysis, rotation method: varimax with Kaiser normalization.

\section{Acknowledgments}

None.

\section{Conflicts of interest}

The authors declare that there is no conflicts of interest.

\section{References}

1. Job Openings and Labor Turnover Survey News Release, Economic News Release. Bureau of Labor Statistics. 2018.

2. Elliott Mest. Coping with housekeeping turnover requires creativity and diligence. Hotel Management. 2017.

3. Hausknecht H, Rodda JM, Howard MJ. Targeted employee retention: Performance-based and job-related differences in reported reasons for staying. (CAHRS Working Paper \#08-06). Ithaca, NY: Cornell University ILR School. Human Resource Management. 2009;48(2):26-288. 
4. Casado MA. Housekeeping Management. Hoboken. $2^{\text {nd }}$ ed. NJ: John Wiley \& Sons; 2012.

5. Groschl S. Diversity management strategies of global hotel groups: A corporate web site based exploration. International Journal of Contemporary Hospitality Management. 2011;23(2):224-240.

6. Jones TJA. Professional Management of Housekeeping Operations. $5^{\text {th }}$ ed. Hoboken. NJ: John Wiley \& Sons; 2008.

7. McDougall J. The Future of HR: Technology that transforms employee experience. 2018.

8. March JG, Simon HE. Organizations. New York: John Wiley. 1958.

9. Porter LW, Steers. Organizational, work, and personal factors in employee turnover and absenteeism. Psychological Bulletin. 1973;80:151-176.

10. Sim J, Mak B, Jones D. A model of customer satisfaction and retention for hotels. Journal of Quality Assurance in Hospitality. 2006;7(3):1-23.

11. Altarawmneh I, Al-Kilani MH. Human Resource Management and Turnover Intentions in the Jordanian Hotel Sector. Research and Practice in Human Resource Management. 2010;18(1):4659.
12. Yang HT, Wan, Fu YJ. Qualitative examination of employee turnover and retention strategies in international tourist hotels in Taiwan. International Journal of Hospitality Management. 2012;31(3):837-848.

13. Chan SH, Kuok OM. A Study of human resources recruitment, selection, and retention issues in the hospitality and tourism Industry in Macau. Journal of Human Resources in Hospitality \& Tourism. 2011;10(4):421-441.

14. Lee C, Lee JW. Analysis of the relationships between the hospitality workforce and job-satisfaction factors according to age, gender, native language and racial-ethnicity. Journal of Tourism \& Hospitality. 2012.

15. Hair JF, Black WC, Babin BJ, et al. Multivariate Data Analysis. $7^{\text {th }}$ ed. Upper Saddle River, NJ: Prentice Hall; 2017.

16. James J. Effect of turnover on performance and effectiveness of human resource practices and policies in retention: A case study of hotel industry. Journal of Hospitality Application and Research. 2011;6(1):65-78. 